\title{
Spontaneous ventilation thoracoscopic thymectomy without muscle relaxant for myasthenia gravis: Comparison with "standard" thoracoscopic thymectomy
}

\author{
Long Jiang, MD, PhD, ${ }^{\mathrm{a}, \mathrm{b}}$ Lieven Depypere, MD, FEBTS, ${ }^{\mathrm{c}}$ Gaetano Rocco, MD, FETCS, ${ }^{\mathrm{d}}$ \\ Jin-Shing Chen, MD, PhD, ${ }^{\mathrm{e}}$ Jun Liu, MD, PhD, ${ }^{\mathrm{a}, \mathrm{b}}$ Wenlong Shao, MD, PhD, ${ }^{\mathrm{a}, \mathrm{b}}$ Hanyu Yang, MD, ${ }^{\mathrm{b}, \mathrm{f}}$ and \\ Jianxing $\mathrm{He}, \mathrm{MD}, \mathrm{PhD},{ }^{\mathrm{a}, \mathrm{b}}$ on behalf of AME Thoracic Surgery Collaborative Group
}

\section{ABSTRACT}

Objectives: Myasthenia gravis (MG) benefits from thymectomy. However, its unpredictable response to muscle relaxants and volatile anesthetic agents may result in muscle weakness and subsequently in postoperative myasthenic crisis. The aim of this study was to determine the surgical outcomes after spontaneous ventilation compared with conventional intubated video-assisted thoracoscopic thymectomy (spontaneous-ventilation video-assisted thoracic thymectomy [SV-VATT] vs intubated video-assisted thoracic thymectomy) in patients with MG.

Methods: Data from all minimally invasive thymectomy procedures performed at our institute between January 2009 and June 2016 were collected. Patient characteristics, perioperative results, and treatment outcomes between SV-VATT (group 1) and the intubated video-assisted thoracic thymectomy (group 2) groups were compared. Furthermore, a propensity score-matching analysis was generated to control for selection bias due to nonrandom group assignment in a 1:1 manner.

Results: Thirty-six patients were included in group 1 and 68 in group 2. Matching of patients according to propensity score resulted in a cohort that consisted of 27 patients in both groups. Patients had similar clinical characteristics in both groups. Operating time $(P=.07)$ and lowest pulse oxygen saturation $(P=.09)$ between the procedures were comparable after matching, but peak $\mathrm{CO}_{2}$ level at the end of expiration was significantly greater in group 1 both before and after matching $(P<.01)$. Moreover, the incidence of postoperative myasthenic crisis and postoperative prolonged tracheal intubation was lower in group 1. The postoperative pain visual analog scale score $(P<.01)$ and the length of hospital stay $(P=.03)$ were shorter in group 1 .

Conclusions: SV-VATT is a feasible procedure in patients with MG. It might be beneficial by reducing postoperative myasthenic crisis and postoperative prolonged tracheal intubation. Further prospective research is needed. ( $\mathrm{J}$ Thorac Cardiovasc Surg 2018;155:1882-9)

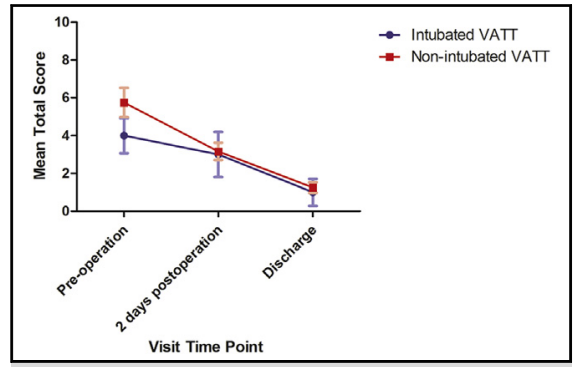

Quantitative Myasthenia Gravis score according to treatment groups.

\section{Central Message}

SV-VATT is a feasible procedure in patients with myasthenia gravis. It might be beneficial by reducing postoperative myasthenic crisis and prolonged intubation.

\section{Perspective}

Patients with myasthenia gravis benefit from thymectomy, but the procedure can be challenging and possibly cause myasthenic crisis due to unpredictable response to muscle relaxants and volatile anesthetic agents. SV-VATT in patients with myasthenia gravis has the potential to reduce postoperative myasthenic crisis and prolonged intubation.

See Editorial Commentary page 1890.
Myasthenia gravis (MG) is an autoimmune disease that is characterized by muscle weakness and fatigue. ${ }^{1}$ The role of the thymus in MG has been suggested by the evidence that $10 \%$ to $15 \%$ of patients present with a thymoma and at least $60 \%$ with thymus hyperplasia or dysplasia.

\footnotetext{
From the Departments of ${ }^{\mathrm{a}}$ Thoracic Surgery and ${ }^{\mathrm{f}}$ Anesthesiology, The First Affiliated Hospital of Guangzhou Medical University, Guangzhou; ${ }^{b}$ Institute of Respiratory Disease \& China State Key Laboratory of Respiratory Disease, Guangzhou, China; ${ }^{c}$ Department of Thoracic Surgery, University Hospital Leuven (Gasthuisberg), Leuven, Belgium; ${ }^{\mathrm{d}}$ Department of Thoracic Surgery, Istituto Nazionale Tumori, Fondazione G. Pascale, IRCCS, Naples, Italy; and ${ }^{\mathrm{e}}$ Department of Thoracic Surgery, National Taiwan University Hospital, Taipei, Taiwan.

Received for publication March 21, 2017; revisions received Oct 19, 2017; accepted for publication Nov 14, 2017; available ahead of print Dec 15, 2017.
}

Beneficial effects of thymectomy in patients with $\mathrm{MG}$ have been described in $40 \%$ to $90 \%$.

Recently, thymectomy in addition to glucocorticoid treatment has been confirmed to improve clinical outcomes compared with glucocorticoid treatment alone in a

\footnotetext{
Address for reprints: Jianxing He, MD, PhD, Department of Thoracic Surgery, The First Affiliated Hospital of Guangzhou Medical University, Guangzhou Institute of Respiratory Disease \& China State Key Laboratory of Respiratory Disease, No. 151, Yanjiang Rd, Guangzhou 510120, China (E-mail: drhe_jianxing@163 com). $0022-5223 / \$ 36.00$

Copyright (c) 2017 by The American Association for Thoracic Surgery https://doi.org/10.1016/j.jtcvs.2017.11.045
} 


$\begin{aligned} & \text { Abbreviations and Acronyms } \\ & \text { ASA }=\text { American Society of Anesthesiologists } \\ & \mathrm{BIS}=\text { bispectral index } \\ & \mathrm{BMI}=\text { body mass index } \\ & \mathrm{EtCO}_{2}= \text { end-tidal carbon dioxide } \\ & \mathrm{IVATT}=\text { intubated video-assisted thoracic } \\ & \text { thymectomy } \\ & \mathrm{MC}=\text { myasthenic crisis } \\ & \mathrm{MG}=\text { myasthenia gravis } \\ & \mathrm{MGFA}= \text { Myasthenia Gravis Foundation of } \\ & \text { America } \\ & \mathrm{NMBA}= \text { neuromuscular blocking agents } \\ & \mathrm{QMG}=\text { Quantitative Myasthenia Gravis } \\ & \mathrm{RR}=\text { respiratory rate } \\ & \mathrm{SpO}=\text { pulse oxygen saturation } \\ & \mathrm{SV}-\mathrm{VATS}= \text { spontaneous-ventilation video-assisted } \\ & \text { thoracoscopic surgery } \\ & \mathrm{SV}-\mathrm{VATT}= \text { spontaneous-ventilation video-assisted } \\ & \text { thoracic thymectomy } \\ & \mathrm{TCI}=\text { target-controlled infusion } \\ & \text { VAS }= \text { visual analog scale } \\ & \text { VATS }= \text { video-assisted thoracoscopic surgery }\end{aligned}$

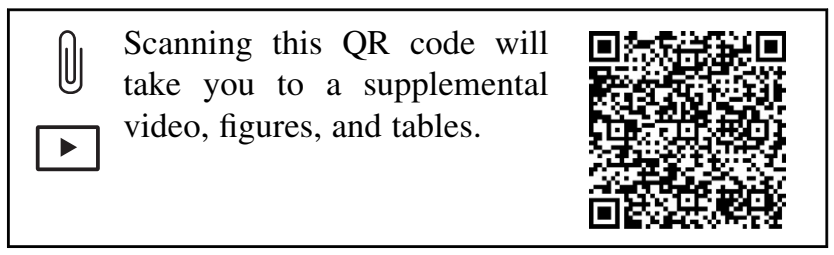

randomized trial in MG patients without thymoma, ${ }^{3}$ with the transsternal approach being accepted as the standard surgical procedure. Minimally invasive methods, such as video-assisted thoracoscopic surgery (VATS), have emerged to avoid a sternotomy, providing a cosmetic advantage and reduction of pain, ${ }^{4}$ blood loss, chest tube duration, and length of hospital stay, with clinical outcomes comparable with sternotomy in appropriately selected patients.

MG is a challenging situation for anesthesiologists because of its unpredictable response to muscle relaxants and increased susceptibility to postoperative respiratory failure, resulting in prolonged dependence on mechanical ventilation. ${ }^{7,8}$ The development of myasthenic crisis (MC) in patients with MG is relatively high $(8 \%-27 \%))^{9-11}$ and postoperative $\mathrm{MC}$ after thymectomy is reported to be from $6 \%$ to $34 \% .{ }^{12-14}$ A previous study reported a significant decrease in neuromuscular transmission with desflurane compared with propofol. ${ }^{15}$ In addition, intubation- and extubation-associated complications are associated with injury of the laryngopharynx and trachea, causing postoperative dysphagia, sore throat, irritating cough, and increased sputum. ${ }^{16,17}$ When intubation exceeds 48 hours after surgery, the frequency of swallowing impairments (dysphagia) is $51 \%$, approximately 10 times greater than that of the surgical population as a whole. ${ }^{18}$ Spontaneous-ventilation video-assisted thoracoscopic surgery (SV-VATS) has been intensively investigated and reported to reduce the adverse effects of tracheal intubation and general anesthesia. ${ }^{19}$ Therefore, it has been advocated as an alternative to conventional intubated VATS with general anesthesia in thymectomy. ${ }^{20,21}$

This exceedingly useful method has raised our expectation of a rapid recovery. It insures no postoperative respiratory muscle weakness due to muscle relaxants and volatile anesthetic agents, which could especially be beneficial in patients with MG. In the present study, we report our initial experience with spontaneous-ventilation video-assisted thoracic thymectomy (SV-VATT) to evaluate its feasibility and efficacy.

\section{MATERIALS AND METHODS Study Design and Patients}

A retrospective analysis of consecutive patients undergoing VATT for MG was undertaken. MG was diagnosed by a neurologist, and patients were examined with acetylcholine receptor antibody studies, Tensilon testing, spirometry, and a computed tomography scan of the chest to diagnose thymoma. Pre- or postoperative clinical severity and outcomes were described based on the Myasthenia Gravis Foundation of America (MGFA) Clinical Classification scheme and Quantitative Myasthenia Gravis (QMG) scoring system. ${ }^{22}$ The latter is a quantification score of clinical symptoms to assess disease severity in $\mathrm{MG}$.

The preoperative regimen of anticholinesterase therapy was maintained during the perioperative phase. Corticosteroids were tapered at remission to the minimal dose required to maintain remission if they were used. The thoracic surgery team, including both surgeons and anesthesiologists, selected the cases on review of medical records. We performed our first SV-VATS procedure in 2012; thus, SV-VATT cases exist only from this year onward. Patients considered appropriate for SV-VATT met the following criteria: age 18 or older and American Society of Anesthesiologists (ASA) grade of I to II. Patients with a bleeding disorder, sleep apnea, evidence of potential pleural adhesions, deranged preoperative blood gases partial pressure of carbon dioxide or oxygen partial pressure, poor preoperative forced expiratory volume in 1 second and forced vital capacity, and potential difficult airway for intubation were not considered suitable for the SV-VATT. Patients with acute exacerbations and MC were not candidates for emergency operations, and thymectomy was avoided until better medical control was gained. Patients with a thymoma that was in contact with the lung or that was seen to be an invasive type by computed tomography or magnetic resonance imaging also were considered unsuitable for SV-VATT.

The control group consisted of patients with MG who underwent VATT with intubated general anesthesia (ie, IVATT) from January 2009 through June 2016. This study was approved by the First Affiliated Hospital of Guangzhou Medical University Research Ethics Committee. Data were obtained by 2 collectors and compiled from medical records and neurologists' notes.

\section{Anesthesia Technique}

Anesthesia was administered as follows: midazolam $(0.06 \mathrm{mg} / \mathrm{kg})$ and atropine $(0.01 \mathrm{mg} / \mathrm{kg})$ were injected intramuscularly 30 minutes before anesthesia. After the patient entered the operating room, his or her 
electrocardiogram, heart rate, blood pressure, pulse oxygen saturation $\left(\mathrm{SpO}_{2}\right)$, end-tidal carbon dioxide $\left(\mathrm{EtCO}_{2}\right)$, respiratory rate $(\mathrm{RR})$, and bispectral index (BIS) were continuously monitored.

\section{Anesthesia in Patients Undergoing SV-VATT}

Anesthesia was induced with the target-controlled infusion (TCI) of propofol (target plasma concentration of $2-3 \mu \mathrm{g} / \mathrm{mL}$ ) and sufentanil 0.1 to $0.2 \mu \mathrm{g} / \mathrm{kg}$. Muscle relaxants were not used. After intravenous rehydration was established, the thoracic epidural catheter was inserted into the T7-T8 or T8-T9 space. In the supine position, a test dose $(2 \mathrm{~mL})$ of $2 \%$ lidocaine was given through the epidural catheter. If signs of spinal anesthesia were not present in 5 minutes, fractionated injection of 10 to $15 \mathrm{~mL}$ of $0.375 \%$ ropivacaine was administered. Before surgery, the anesthesia level should reach between T2 and T10. During the procedure, a laryngeal mask was used for oxygen inhalation, with an oxygen flow of 4 to $5 \mathrm{~L} / \mathrm{min}$, keeping oxygen saturation above $95 \%$. Anesthesia was maintained with TCI of propofol (target plasma concentration of $1-2 \mu \mathrm{g} / \mathrm{mL}$ ) and dexmedetomidine 0.5 to $1 \mu \mathrm{g} / \mathrm{kg} / \mathrm{h}$. A single dose of anesthetic agent was administered at the beginning of the operation. BIS monitoring was maintained at 40 to 60 during the operation. The spontaneous respiration rate was 12 to 20 breaths per minute. During spontaneous ventilation procedures, a gradual and natural collapse of the lung occurs; this allows maximal visualization after creating the incisions and opening the ipsilateral pleura. To reduce cough induced by thoracoscopic manipulation, $6 \mathrm{~mL}$ of $2 \%$ lidocaine was sprayed on the lung surface under thoracoscopic guidance. The epidural catheter was removed after the surgery in the operating room.

\section{Anesthesia in Patients Undergoing IVATT}

Patients were induced by the TCI of propofol (target plasma concentration of $3 \mu \mathrm{g} / \mathrm{mL}$ ) and sufentanil $0.4 \mu \mathrm{g} / \mathrm{kg}$ and cisatracurium $0.2 \mathrm{mg} /$ $\mathrm{kg}$. After 3 minutes of mask oxygen ventilation, the double-lumen tube was inserted via laryngoscopy and a flexible bronchofiberscope was used to verify the correct positioning of the tube in the trachea. Volume-controlled ventilation with tidal volume 6 to $8 \mathrm{~mL} / \mathrm{kg}$ was used during the surgery. Anesthesia was maintained with sevoflurane $1 \%$ to $3 \% \mathrm{TCI}$ of propofol and remifentanil 0.05 to $0.1 \mu \mathrm{g} / \mathrm{kg} / \mathrm{min}$. The concentration of anesthetics was adjusted with BIS maintained within 40 to 60 . The patients were extubated in the operating theater or remained intubated and were sent to the intensive care unit postoperatively. The timing for extubation was determined by the anesthesiologist according to the clinical outcomes. We used train-of-four monitoring during surgery and ensured full recovery (train-of-four ratio $\geq 90 \%$ ) before terminating the anesthetics.

\section{Surgical Management}

The VATT procedures were the same in both groups as described by Wright and Keating. ${ }^{23}$ We did not use $\mathrm{CO}_{2}$ insufflation in the cavity in either population (intubated or spontaneous ventilating). The patient was tilted $30^{\circ}$ lateral in a semisupine position with a roll under the shoulder. The ipsilateral arm was held abducted over a padded L screen to expose the axilla for port placement. Three 10 -mm ports were created. A $30^{\circ}$ angled camera was placed in the most lateral 10 -mm port. The surgical approach was exclusively from the side of the thymus to enable safe dissection under direct vision. The nontumoral part of the thymus and perithymic fat were always dissected first and used for grasping and traction when dissecting the thymus to minimize the risk of capsular damage. All specimens were safely removed via a specimen bag by enlarging one of the anterior port incisions. Any bleeding or air leak was managed by reinforcement sutures using 4/0 PROLENE (Ethicon, Somerville, NJ) or application of sealants such as Biopaper (Datsing Bio-Tech Co Ltd, Beijing, China). Finally, a 24-F chest tube was placed at the end of the operation (Video 1).

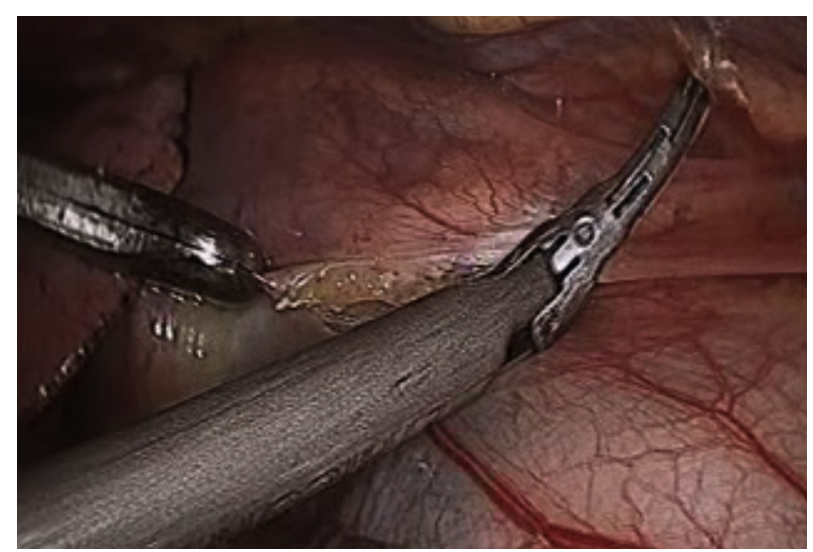

VIDEO 1. The surgical procedure for spontaneous-ventilation video-assisted thoracic thymectomy. Video available at: http://www.jtcvsonline.org/ article/S0022-5223(17)32726-5/fulltext.

\section{Postoperative Follow-up}

All patients were transferred to the postanesthesia care unit for recovery. The extubation criteria for weaning from mechanical ventilation included (1) clear consciousness; (2) stable spontaneous ventilation ( $\mathrm{RR}<30$ breaths/min, increase in $\mathrm{RR}<10$ breaths/min); (3) normal gas exchanges with low-flow oxygen inhalation $\left(\mathrm{SpO}_{2}>90 \%\right.$; oxygen tension $>80 \mathrm{~mm} \mathrm{Hg} ; \mathrm{pH}>7.30$; increase in arterial carbon dioxide pressure $<10 \mathrm{~mm} \mathrm{Hg}$ ); and (4) hemodynamic stability (increase in systolic blood pressure $<10 \mathrm{~mm} \mathrm{Hg}$ ). Chest radiograph was performed for evaluation. Fentanyl patch or nonsteroidal anti-inflammatory drugs were offered to patients in the nonintubated group. Postoperative analgesics in the intubated group included epidural self-controlled infusion of dezocine, sufentanil, and tropisetron. Formal pain assessment for the study was carried out on the morning of postoperative day 1 by use of the visual analog scales (VAS: 0 is completely pain-free and 10 is hard to tolerate) $.^{24} \mathrm{Com}-$ plications after surgery including air leaks $>3$ days, pulmonary infection, atelectasis, MC, and sore throat were recorded. Conversions to intubation and delayed extubation were also recorded. A postoperative MC was defined by the presence of (1) respiratory failure induced by neuromuscular weakness after surgery with a prolonged postoperative intubation (more than 48 hours); (2) extubation within 24 hours after surgery, but recurrence of neuromuscular weakness that required reintubation or resuscitation support in the following 2 weeks; and (3) exclusion of cholinergic crisis or respiratory failure due to phrenic paralysis or other diseases. ${ }^{25}$

\section{Primary Outcomes and Statistical Analysis}

The primary outcomes were surgical mortality, rates of conversion to intubated surgery, surgical duration, the lowest $\mathrm{SpO}_{2}$ and peak $\mathrm{EtCO}_{2}$ during the operation, and postoperative complications. The secondary outcomes reflected the efficacy including duration of ventilator use postoperatively, MG remission situation, and length of hospital stay.

The propensity score-matched cohort was created by the use of logistic regression to calculate propensity scores, that is, the probability (propensity) of an individual receiving the treatment based on the patient's observed time-invariant pretreatment baseline variables as proposed by Rosenbaum and Rubin. ${ }^{26}$ The following potential baseline prognostic and risk factors were included in the model: age, sex, body mass index (BMI), smoking status, comorbidity, pulmonary function tests, preoperative medication, and MGFA classification. By using a 1:1 nearest neighbor matching algorithm that pairs patients with the closest propensity scores within a defined limit (calipers of width equal to 0.2 ), we found that the propensity score yielded 2 well-matched cohorts of 27 
patients (logistic regression estimation algorithm). We compared standardized differences for all covariates between prematch imbalance and postmatch balance. ${ }^{27}$

Continuous data are presented as mean \pm standard deviation and were analyzed with 2-sample Student $t$ tests for independent data. Categorical variables are given as a count and percentage of patients and compared with the $\chi^{2}$ or Fisher exact test. $P$ values $<.05$ were considered statistically significant. The QMG score was used to assess the MG patients pre- and postoperation. ${ }^{28}$ All tests were 2 -sided, with an a-level of 0.05 . SPSS software (SPSS version 22.0; IBM Corp, Armonk, NY) and R (R version 2.15.3, 2013; The R Foundation, Vienna, Austria) were used for all statistical evaluations.

\section{RESULTS}

From March 2012 through June 2016, 36 patients underwent SV-VATT and were included for analysis. The control group consisted of 68 patients who underwent IVATT from January 2009 through June 2016. The 2 groups did not differ in age, sex, BMI, smoking status, pulmonary function, tumor size, MGFA classification, ASA classification, or pathologic diagnosis. The percentage of thymoma between groups showed no difference (SV-VATT: $47.2 \%$ vs IVATT: $52.9 \%, P=.68$ ), and there was no difference between the 2 groups regarding Masaoka stage, World Health Organization classification, or the number of patients who received adjuvant therapy. The preoperative duration of symptoms and medication are presented in Table E1.

According to operative and anesthesia results, surgical duration and intraoperative urine output were comparable in both groups. During the procedures, the detectable mean lowest $\mathrm{SpO}_{2}$ was not significantly different (SVVATT: $96.8 \pm 2.4$ vs IVATT: $98 \pm 2.8, P=.1$ ). However, the mean peak $\mathrm{EtCO}_{2}$ in the SV-VATT group was greater than that detected in the IVATT group $(41.4 \pm 3.5$ vs $37 \pm 4.3 \mathrm{~mm} \mathrm{Hg}, P<.01$ ) due to mild hypercapnia under nonintubated anesthesia. Conversion to intubated ventilation and thoracotomy was required in one patient as a result of dense adhesions in the right lung (Table E2).

The improvement of MG status after surgical treatment is shown in Figure 1. There was no significant difference between QMG scores of the 2 groups $(P=.07)$. During the perioperative phase, no mortality was noted in either group. More complications developed in the IVATT group compared with the SV-VATT group (IVATT: 34 vs SVVATT: $3, P<.01)$. Complications of the IVATT group included sore throat in $10(14.7 \%)$, air leak in $5(7.4 \%)$, and pulmonary infection in $5(7.4 \%)$ patients. MC occurred in $14(20.6 \%)$ patients in the IVATT group compared with 1 $(2.8 \%)$ patient in the SV-VATT group $(P=.02)$. Delayed extubation was found in $18(26.5 \%)$ patients in the IVATT group, whereas only the 1 patient $(2.8 \%)$ who suffered from MC required intubation postoperatively in the SV-VATT group $(P<.01)$. The average length of postoperative intubation was $16.9 \pm 27.7$ hours (range, 1-140 hours). Statistical

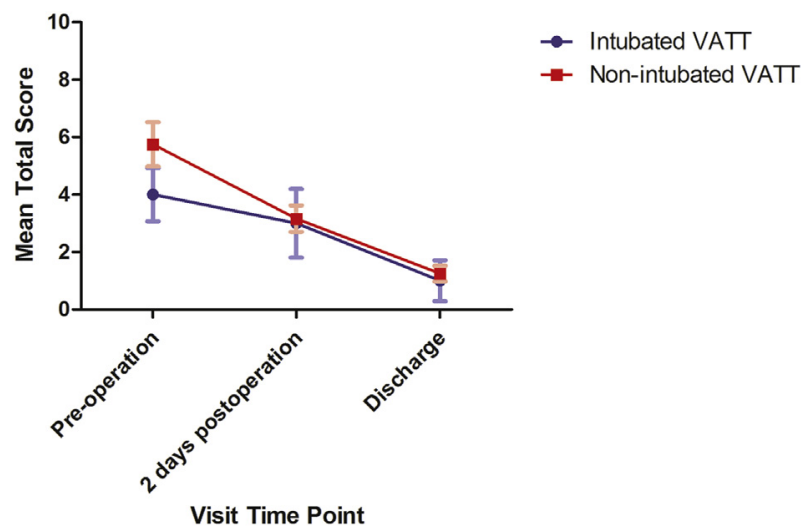

FIGURE 1. Quantitative Myasthenia Gravis Score according to treatment groups. The vertical bars refer to 25 th to 75 th percentile. Scores range from 0 to 39 , with greater scores on each of 13 items indicating more severe disease. The scores were measured at 3 time points: preoperation, 2 days postoperation, and discharge. VATT, Video-assisted thoracic thymectomy.

analysis also showed that patients in the SV-VATT group had shorter periods of postoperative hospital stay $(P=.02)$. Details are shown in Table E3.

Matching of patients according to propensity score resulted in a cohort that consisted of 27 patients in each group. The overall balance test ${ }^{29}$ suggested substantial covariate balance across the groups $(P=.988)$. A dot plot of standardized mean differences for all covariates before and after matching is shown in Figure E1. Those undergoing SVVATT had similar distributions for age, sex, BMI, smoking status, comorbidity, ASA grade, pulmonary function tests, MGFA classification, preoperative medication, positive acetylcholine receptor antibody, and preoperative duration of symptoms to those undergoing IVATT. Baseline characteristics of matched patients can be found in Table 1.

After matching, no differences were found in surgical duration, mean lowest $\mathrm{SpO}_{2}$, or intraoperative urine output. However, the mean peak $\mathrm{EtCO}_{2}$ in the SV-VATT group was still greater $(43.7 \pm 4.8$ vs $37.6 \pm 5.3 \mathrm{~mm} \mathrm{Hg}, P<.01)$. More complications occurred in the IVATT group than the SV-VATT group $(P<.01)$. Among these, MC occurred in $3(11.1 \%)$ patients in the IVATT group but 0 in SV-VATT group. The postoperative pain VAS score was lower in SV-VATT $(2.5 \pm 0.8$ vs $3.1 \pm 0.8, P<.01)$ and average length of hospitalization of the SV-VATT group was shorter than the IVATT group $(6.6 \pm 3.0$ vs $8.6 \pm 3.7$ days, $P=.03)$ (Table 2).

\section{DISCUSSION}

With this propensity score-matched analysis, we demonstrated that SV-VATT is a feasible technique. In patients with MG, avoiding muscle relaxants and volatile anesthetic agents may allow relief of symptoms, fast recovery, and early discharge from the hospital. 
TABLE 1. Baseline characteristics of matched patients

\begin{tabular}{|c|c|c|c|}
\hline Variable & SV-VATT $(n=27)(\%)$ & IVATT $(\mathbf{n}=27)(\%)$ & $P$ value \\
\hline Age, y & $40.7 \pm 17.6$ & $40.5 \pm 16.1$ & .96 \\
\hline Sex, male/female & $13 / 14$ & $14 / 13$ & \\
\hline BMI, $\mathrm{kg} / \mathrm{m}^{2}$ & $22.8 \pm 3.4$ & $22.5 \pm 4.0$ & .76 \\
\hline Smoking status & $4(14.8)$ & $3(11.1)$ & \\
\hline $\begin{array}{l}\text { Comorbidity } \\
\text { Hypertension } \\
\text { Diabetes mellitus } \\
\text { Digestive disease } \\
\text { Other (bronchiectasis, rheumatoid disease, gynecologic diseases) }\end{array}$ & $\begin{array}{c}4(14.8) \\
0 \\
4(14.8) \\
6(22.2)\end{array}$ & $\begin{array}{c}2(7.4) \\
0 \\
3(11.1) \\
4(14.8)\end{array}$ & .93 \\
\hline $\begin{array}{l}\text { ASA physical status class } \\
\text { I } \\
\text { II }\end{array}$ & $\begin{array}{r}19(70.4) \\
8(29.6)\end{array}$ & $\begin{array}{l}12(44.4) \\
15(55.6)\end{array}$ & .10 \\
\hline $\begin{array}{l}\text { MGFA classification } \\
\text { I } \\
\text { II } \\
\text { III } \\
\text { IV }\end{array}$ & $\begin{aligned} 11 & (40.7) \\
8 & (29.6) \\
6 & (22.2) \\
2 & (7.4)\end{aligned}$ & $\begin{aligned} 13 & (48.1) \\
9 & (33.3) \\
3 & (11.1) \\
2 & (7.4)\end{aligned}$ & .75 \\
\hline $\begin{array}{l}\text { Pulmonary function tests } \\
\text { FVC, L } \\
\mathrm{FEV}_{1}, \mathrm{~L}\end{array}$ & $\begin{array}{l}3.1 \pm 0.9 \\
2.5 \pm 0.7\end{array}$ & $\begin{array}{l}3.2 \pm 1.0 \\
2.7 \pm 0.8\end{array}$ & $\begin{array}{l}.57 \\
.21\end{array}$ \\
\hline $\begin{array}{l}\text { Preoperative medication } \\
\text { CI } \\
\text { CI + corticoid } \\
\text { CI + IVIg } \\
\text { CI + corticoid + IVIg } \\
\text { Corticoid + IVIg } \\
\text { AChR antibodies }+\end{array}$ & $\begin{array}{l}10(37) \\
3(11.1) \\
5(18.5) \\
9(33.3) \\
0\end{array}$ & $\begin{array}{l}11(40.7) \\
6(22.2) \\
2(7.4) \\
4(14.8) \\
4(14.8)\end{array}$ & .08 \\
\hline $\begin{array}{l}\text { AChR antibodies }+ \\
\text { Preoperative duration of symptoms, mo }\end{array}$ & $25(92.6)$ & $22(81.5)$ & .42 \\
\hline $\begin{array}{l}\text { Preoperative duration of symptoms, mo } \\
\quad<12 \\
>12\end{array}$ & $\begin{array}{l}10(37) \\
17(63)\end{array}$ & $\begin{array}{l}13(48.1) \\
14(51.9)\end{array}$ & .58 \\
\hline
\end{tabular}

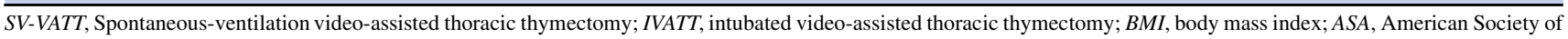
Anesthesiologists; $M G F A$, Myasthenia Gravis Foundation of America; $F V C$, forced vital capacity; $F E V_{l}$, forced expiratory volume in 1 second; $C I$, cholinesterase inhibitors; IVIg, intravenous immunoglobulin; $A C h R$, acetylcholine receptor.

To avoid intubation-related and mechanical ventilationassociated complications, thoracoscopic surgery without endotracheal intubation was recently described in selected patients with thoracic disease. ${ }^{30-32}$ In 2004, Pompeo and colleagues $^{31}$ reported the first successful SV-VATS wedge resections for solitary pulmonary nodules under thoracic epidural anesthesia. After that, its applications have broadened to include pulmonary disease and different mediastinal surgical procedures. Generally, results from these studies found this method to be technically feasible and safe with lower complication rates, shorter length of hospital stay, and better patient satisfaction. ${ }^{19,33}$ In regard to patients with MG with its unpredictable response to muscle relaxants and increased susceptibility to postoperative respiratory failure, SV-VATS was thought to be the solution because of discontinuance of muscle relaxants and volatile anesthetic agents in SV anesthesia.
Many complications are caused by intubation and extubation procedures ${ }^{16,17}$; also, sometimes their severity is increased after the time of intubation. ${ }^{18}$ In addition, the neuromuscular transmission decreased significantly with the use of desflurane compared with propofol. ${ }^{15}$ In the results of our study, the complication rate in the SV-VATT group was much lower than that of the IVATT group. The incidence rate of MC in our study is $20.6 \%$, which is still in accordance with existing literature $(6 \%-34 \%))^{12-14} \mathrm{MC}$ occurred more in the IVATT group than the SV-VATT group. The 1 patient who experienced $\mathrm{MC}$ in the SV-VATT group is also the only patient who had both MG associated with thymoma and toxic multinodular goiter. Moreover, she was 70 years of age. Extubation was delayed in more patients in the IVATT group in case of myasthenic weakness before and after matching. In the previous unmatched series, only 1 procedure in the SV-VATT 
TABLE 2. Surgical outcomes of matched patients

\begin{tabular}{lccc}
\hline \multicolumn{1}{c}{ Variable } & SV-VATT $(\mathbf{n}=\mathbf{2 7})$ & IVATT $(\mathbf{n}=\mathbf{2 7})$ & $\boldsymbol{P}$ value \\
\hline Surgical duration, min & $134.0 \pm 39.7$ & $159.9 \pm 59.6$ & .07 \\
$\mathrm{SpO}_{2}, \%$ & $96.6 \pm 2.6$ & $98.0 \pm 2.8$ & .09 \\
$\mathrm{EtCO}_{2}, \mathrm{~mm} \mathrm{Hg}$ & $43.7 \pm 4.8$ & $37.6 \pm 5.3$ & $<.01$ \\
Urine output, $\mathrm{mL}$ & $527.0 \pm 247.0$ & $521.5 \pm 293.6$ & .94 \\
Complications & & $5(18.5)$ & $<.01$ \\
Sore throat & 0 & $2(7.4)$ & .05 \\
Air leak $>3$ d & 0 & $3(11.1)$ & .49 \\
Pulmonary infection & 0 & 0 & .23 \\
Atelectasis & $1(3.7)$ & $3(11.1)$ & .1 \\
Myasthenic crisis & 0 & $6(22.2)$ & .23 \\
Postoperative tracheal intubation time $>1 \mathrm{~d}$ & 0 & $3.1 \pm 0.8$ \\
Postoperative pain VAS score & $2.5 \pm 0.8$ & $8.6 \pm 3.7$ \\
Hospital stay, d & $6.6 \pm 3.0$ & .02 \\
\hline
\end{tabular}

$\mathrm{SV}$-VATT, Spontaneous-ventilation video-assisted thoracic thymectomy; $I V A T T$, intubated video-assisted thoracic thymectomy; $\mathrm{SpO}_{2}$, pulse oxygen saturation; $E t C \mathrm{O}_{2}$, end-tidal carbon dioxide; $V A S$, visual analog scale.

group was converted to intubated ventilation; this particular case also required conversion to an open thoracotomy as a result of dense adhesions. Furthermore, the SV-VATT group had shorter periods of postoperative hospital stay.

Because of the constraints of our medical system (where primary care in a patient's hometown is not widely available, which may even encourage longer hospital stays), the length of hospital stay, although significant, may have limited usefulness when comparing with other countries. Sometimes intraoperative conversion to general anesthesia is inevitable, and the surgical team must have a plan to minimize the risk to the patient. Even when some inducing factors of adhesions are excluded, however, there is not an effective way to assess the extent of adhesions preoperatively. To ensure the patient safety, a clearly defined protocol for urgent intubation during the procedure must be determined. In any case, continuous and effective communication between surgical and anesthetic teams is paramount.

For patients with MG, intubation techniques that use combined epidural and intravenous anesthesia, without muscle relaxants, have been employed. ${ }^{30,34-36}$ The respiratory insufficiency introduced by volatile agents and the complications due to endotracheal tube placement can continue postoperatively and may require reintubation or prolonged intubation. ${ }^{37}$ Matsumoto and colleagues ${ }^{38}$ described an awake endoscopic thymectomy through an infrasternal approach using sternal lifting and showed that it was safe and beneficial for fast recovery. Moreover, it is important to note that during the extended thymectomy, the contralateral pleura can easily be injured when fatty tissue near a phrenic nerve is dissected. Tsunezuka and colleagues ${ }^{30}$ described the results of thymectomy performed in 3 patients with MG under awake epidural anesthesia. They found that hemodynamics and the respiratory state are not severely changed by unilateral pleural injury alone.
In the present study, we opened the contralateral pleura sequentially in all patients to confirm that the thymus and all surrounding tissue were dissected. The 2 groups had comparable mean lowest $\mathrm{SpO}_{2}$ intraoperatively; however, the mean peak $\mathrm{EtCO}_{2}$ was somewhat greater in the SVVATT group. We use a laryngeal mask as a safety precaution for ventilatory management to maintain satisfactory oxygenation during spontaneous respiration. Carbon dioxide rebreathing might occur; our experience showed that such mild hypercapnia was permissive and did not affect the hemodynamics or surgical procedures. Although hypercapnia may exert multiple physiologic effects on different organs, particularly the pulmonary, cardiovascular, and cerebrovascular systems, undesired physiologic effects of nonmassive respiratory acidosis (arterial carbon dioxide tension $\leq 80 \mathrm{~mm} \mathrm{Hg}$, arterial $\mathrm{pH} \geq 7.15$ ) are reversible and mostly minor. ${ }^{39}$ In addition, it has been suggested that permissive hypercapnia may improve hemodynamics and the ventilation/perfusion match and have protective effects in inflammatory response. ${ }^{40}$

Since the first VATS under spontaneous ventilation without intubation was performed with epidural analgesia,${ }^{31}$ we have incorporated this approach in our patients to avoid potential intubation and ventilation associated issues and postoperative pain. However, we recognize that epidural anesthesia is not risk free and can lead to sideeffects of sympathetic blockade such as hypotension and bradycardia, urinary retention, epidural hematoma, and infection. ${ }^{41}$ The overall incidence of complications after thoracic epidural catheterization was $3.1 \%$ in a study by Giebler and colleagues. ${ }^{42}$ Recently, we have begun exploring the possibility of using only wound infiltration, intercostal nerve blockade, and paravertebral blockade to eliminate the need for epidural anesthesia.

The following limitations must be acknowledged: (1) The study was retrospective and the comparison was based 
on historical controls. In addition, even though the propensity-score matching method was used, selection bias still existed; risk-adjusted analysis was merely for hypothesis generation. (2) The epidural usage was determined as per protocol at that time, as well as the use of neuromuscular blocking agents (NMBA). Although some case reports have described double-lumen placement without NMBA, ${ }^{43,44}$ in our conventional opinion, placing a double-lumen tube without NMBA is difficult and potentially dangerous. (3) The significantly different strategy in postoperative analgesia may also have influenced important implications on the measured postoperative outcomes. The differences in VAS scores between the 2 groups may be a result of the following: (A) the number of patients in each group was small, the threshold of pain may vary largely, and the basal scores were low in both groups; and (B) pain control in the SV-VATS group may be influenced by intraoperative intercostal blocks and local infiltration anesthesia, postoperative fentanyl patch, and analgesic medication and injection, whereas pain control in the IVATT group may be influenced by the epidural catheter. (4) In our hospital system, we re-evaluate patients 1 month postoperatively but do not require long-term re-examination, which might preclude efficacy outcomes data reporting. (5) The use of a laryngeal mask airway may also introduce associated complications such as air leak, mask displacement, gastric insufflation, reflux, aspiration, etc. (6) For ocular nonthymomatous MG patients, acetylcholinesterase inhibitors (eg, pyridostigmine) are recommended as the mainstay of pharmacotherapy. Surgical treatment may be used if this agent is unsuccessful, and the surgical risk should be considered. More evidence is required from further studies to confirm the effect of surgical resection in this subgroup.

We conclude that SV-VATT is a feasible procedure. Compared with IVATT, the procedure might be beneficial in patients with MG by reducing the incidence of myasthenic weakness and intubation-related complications. Further prospective research on this topic is needed.

\section{Conflict of Interest Statement}

Authors have nothing to disclose with regard to commercial support.

\section{References}

1. Gilhus NE, Verschuuren JJ. Myasthenia gravis: subgroup classification and therapeutic strategies. Lancet Neurol. 2015;14:1023-36.

2. Chevalley C, Spiliopoulos A, de Perrot M, Tschopp JM, Licker M. Perioperative medical management and outcome following thymectomy for myasthenia gravis. Can J Anaesth. 2001;48:446-51.

3. Wolfe GI, Kaminski HJ, Aban IB, Minisman G, Kuo HC, Marx A, et al. Randomized trial of thymectomy in myasthenia gravis. N Engl J Med. 2016;375:511-22.

4. Sakamaki Y, Kido T, Yasukawa M. Alternative choices of total and partial thymectomy in video-assisted resection of noninvasive thymomas. Surg Endosc. 2008;22:1272-7.

5. Friedant AJ, Handorf EA, Su S, Scott WJ. Minimally invasive versus open thymectomy for thymic malignancies: systematic review and meta-analysis. J Thorac Oncol. 2016;11:30-8.

6. Hess NR, Sarkaria IS, Pennathur A, Levy RM, Christie NA, Luketich JD. Minimally invasive versus open thymectomy: a systematic review of surgical techniques, patient demographics, and perioperative outcomes. Ann Cardiothorac Surg. 2016;5:1-9.

7. Mori T, Yoshioka M, Watanabe K, Iwatani K, Kobayashi H, Terasaki H, et al. Changes in respiratory condition after thymectomy for patients with myasthenia gravis. Ann Thorac Cardiovasc Surg. 2003;9:93-7.

8. Gracey DR, Divertie MB, Howard FM Jr, Payne WS. Postoperative respiratory care after transsternal thymectomy in myasthenia gravis. A 3-year experience in 53 patients. Chest. 1984;86:67-71.

9. Berrouschot J, Baumann I, Kalischewski P, Sterker M, Schneider D. Therapy of myasthenic crisis. Crit Care Med. 1997;25:1228-35.

10. Lacomis D. Myasthenic crisis. Neurocrit Care. 2005;3:189-94.

11. Thomas CE, Mayer SA, Gungor Y, Swarup R, Webster EA, Chang I, et al. Myasthenic crisis: clinical features, mortality, complications, and risk factors for prolonged intubation. Neurology. 1997;48:1253-60.

12. Bulkley GB, Bass KN, Stephenson GR, Diener-West M, George S, Reilly PA, et al. Extended cervicomediastinal thymectomy in the integrated management of myasthenia gravis. Ann Surg. 1997;226:324-34; discussion 334-5.

13. Hatton PD, Diehl JT, Daly BD, Rheinlander HF, Johnson H, Schrader JB, et al. Transsternal radical thymectomy for myasthenia gravis: a 15-year review. Ann Thorac Surg. 1989; 47:838-40.

14. Kas J, Kiss D, Simon V, Svastics E, Major L, Szobor A. Decade-long experience with surgical therapy of myasthenia gravis: early complications of 324 transsternal thymectomies. Ann Thorac Surg. 2001;72:1691-7.

15. Gritti P, Carrara B, Khotcholava M, Bortolotti G, Giardini D, Lanterna LA, et al. The use of desflurane or propofol in combination with remifentanil in myasthenic patients undergoing a video-assisted thoracoscopic-extended thymectomy. Acta Anaesthesiol Scand. 2009;53:380-9.

16. Gothard J. Lung injury after thoracic surgery and one-lung ventilation. Curr Opin Anaesthesiol. 2006;19:5-10.

17. Fitzmaurice BG, Brodsky JB. Airway rupture from double-lumen tubes. J Cardiothorac Vasc Anesth. 1999;13:322-9.

18. Barker J, Martino R, Reichardt B, Hickey EJ, Ralph-Edwards A. Incidence and impact of dysphagia in patients receiving prolonged endotracheal intubation after cardiac surgery. Can J Surg. 2009;52:119-24.

19. Chen JS, Cheng YJ, Hung MH, Tseng YD, Chen KC, Lee YC. Nonintubated thoracoscopic lobectomy for lung cancer. Ann Surg. 2011;254:1038-43.

20. Al-Abdullatief M, Wahood A, Al-Shirawi N, Arabi Y, Wahba M, Al-Jumah M, et al. Awake anaesthesia for major thoracic surgical procedures: an observational study. Eur J Cardiothorac Surg. 2007;32:346-50.

21. Jiang L, Liu J, Shao W, Li J, He J. Non-intubated subxiphoid uniportal videoassisted thoracoscopic thymectomy using glasses-free 3D vision. J Thorac Dis. 2016;8:E1602-4.

22. Jaretzki A III, Barohn RJ, Ernstoff RM, Kaminski HJ, Keesey JC, Penn AS, et al. Myasthenia gravis: recommendations for clinical research standards. Task Force of the Medical Scientific Advisory Board of the Myasthenia Gravis Foundation of America. Ann Thorac Surg. 2000;70:327-34.

23. Wright GM, Keating C. Totally endoscopic techniques: right-sided thoracoscopic thymectomy. In: Lavini C, ed. Thymus Gland Pathology: Clinical, Diagnostic and Therapeutic Features. Milan, Italy: Springer-Verlag Italia; 2008:201-6.

24. Perez-Ruvalcaba I, Sanchez-Hernandez V, Mercado-Sesma AR. Effect of a combined continuous and intermittent transcutaneous electrical nerve stimulation on pain perception of burn patients evaluated by visual analog scale: a pilot study. Local Reg Anesth. 2015;8:119-22.

25. Leuzzi G, Meacci E, Cusumano G, Cesario A, Chiappetta M, Dall'armi V, et al. Thymectomy in myasthenia gravis: proposal for a predictive score of postoperative myasthenic crisis. Eur J Cardiothorac Surg. 2014;45:e76-88; discussion e88.

26. Rosenbaum P, Rubin D. The central role of the propensity score in observational studies for causal effects. Biometrika. 1983;70:41-55.

27. McMurry TL, Hu Y, Blackstone EH, Kozower BD. Propensity scores: methods, considerations, and applications in the Journal of Thoracic and Cardiovascular Surgery. J Thorac Cardiovasc Surg. 2015;150:14-9.

28. Barohn RJ, McIntire D, Herbelin L, Wolfe GI, Nations S, Bryan WW. Reliability testing of the quantitative myasthenia gravis score. Ann N Y Acad Sci. 1998;841: 769-72.

29. Hansen BB, Bowers J. Covariate balance in simple, stratified and clustered comparative studies. Stat Sci. 2008;23:219-36. 
30. Tsunezuka Y, Oda M, Matsumoto I, Tamura M, Watanabe G. Extended thymectomy in patients with myasthenia gravis with high thoracic epidural anesthesia alone. World J Surg. 2004;28:962-5; discussion 965-6.

31. Pompeo E, Mineo D, Rogliani P, Sabato AF, Mineo TC. Feasibility and results of awake thoracoscopic resection of solitary pulmonary nodules. Ann Thorac Surg. 2004;78:1761-8.

32. Mukaida T, Andou A, Date H, Aoe M, Shimizu N. Thoracoscopic operation for secondary pneumothorax under local and epidural anesthesia in high-risk patients. Ann Thorac Surg. 1998;65:924-6.

33. Liu J, Cui F, Li S, Chen H, Shao W, Liang L, et al. Nonintubated video-assisted thoracoscopic surgery under epidural anesthesia compared with conventional anesthetic option: a randomized control study. Surg Innov. 2015;22:123-30.

34. Della Rocca G, Coccia C, Diana L, Pompei L, Costa MG, Tomaselli E, et al. Propofol or sevoflurane anesthesia without muscle relaxants allow the early extubation of myasthenic patients. Can J Anaesth. 2003;50:547-52.

35. O'Flaherty D, Pennant JH, Rao K, Giesecke AH. Total intravenous anesthesia with propofol for transsternal thymectomy in myasthenia gravis. J Clin Anesth. 1992;4:241-4.

36. Fujita Y, Moriyama S, Aoki S, Yoshizawa S, Tomita M, Kojima T, et al. Estimation of the success rate of anesthetic management for thymectomy in patients with myasthenia gravis treated without muscle relaxants: a retrospective observational cohort study. J Anesth. 2015;29:794-7.

37. Pompeo E, Mineo TC. Awake thoracic surgery: a historical perspective. In: Pompeo E, ed. Awake Thoracic Surgery. Sharja: U.A.E.: Bentham Science Publishers; 2012:3-8.
38. Matsumoto I, Oda M, Watanabe G. Awake endoscopic thymectomy via an infrasternal approach using sternal lifting. Thorac Cardiovasc Surg. 2008; 56:311-3.

39. Feihl F, Perret C. Permissive hypercapnia. How permissive should we be? Am J Respir Crit Care Med. 1994;150:1722-37.

40. Sinclair SE, Kregenow DA, Lamm WJ, Starr IR, Chi EY, Hlastala MP. Hypercapnic acidosis is protective in an in vivo model of ventilator-induced lung injury. Am J Respir Crit Care Med. 2002;166:403-8.

41. Baidya DK, Khanna P, Maitra S. Analgesic efficacy and safety of thoracic paravertebral and epidural analgesia for thoracic surgery: a systematic review and meta-analysis. Interact Cardiovasc Thorac Surg. 2014;18:626-35.

42. Giebler RM, Scherer RU, Peters J. Incidence of neurologic complications related to thoracic epidural catheterization. Anesthesiology. 1997 86:55-63.

43. El-Dawlatly AA. Anesthesia for thoracoscopic thymectomy: modified nonmuscle relaxant technique-case reports. Middle East J Anaesthesiol. 2007;19: 219-24.

44. Adate K, Shinde A, Thombre S, Harnagle K. Management of thoracoscopic thymectomy in a myasthenia gravis patient. Indian J Anaesth. 2011;55:77-8.

Key Words: myasthenia gravis, video-assisted thoracoscopic thymectomy, spontaneous ventilation 


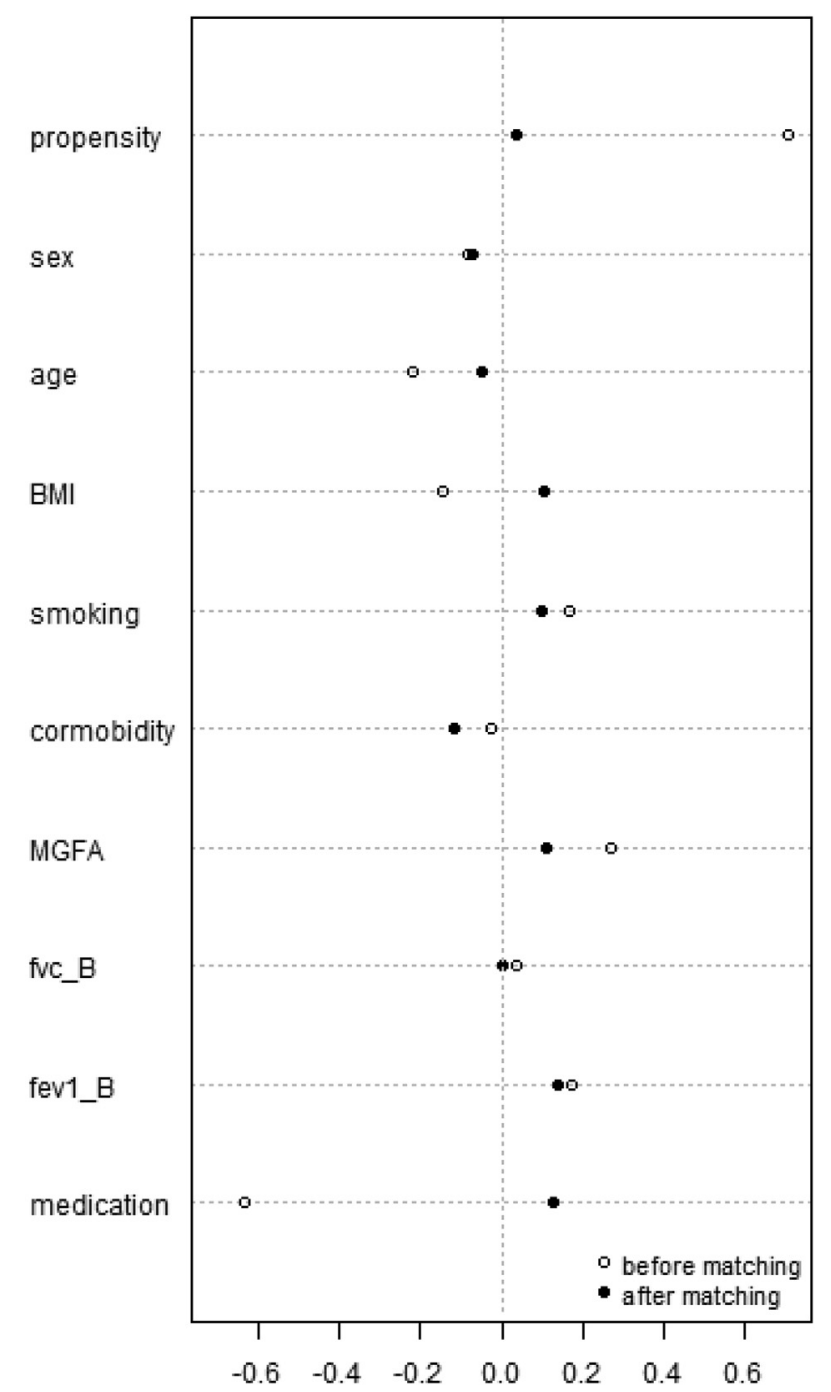

FIGURE E1. Dot plot of standardized mean differences for all covariates before and after matching. BMI, Body mass index; MGFA, Myasthenia Gravis Foundation of America. 
TABLE E1. Clinical characteristics of total population

\begin{tabular}{|c|c|c|c|}
\hline Variable & SV-VATT $(n=36)(\%)$ & IVATT $(n=68)(\%)$ & $P$ value \\
\hline Age, $y$ & $38 \pm 17$ & $42 \pm 16$ & .26 \\
\hline Sex, male/female & $17 / 19$ & $35 / 33$ & .84 \\
\hline BMI, $\mathrm{kg} / \mathrm{m}^{2}$ & $22.4 \pm 3.4$ & $23 \pm 3.8$ & .33 \\
\hline Smoking status & $6(16.7)$ & $6(8.8)$ & .22 \\
\hline $\begin{array}{l}\text { Comorbidity } \\
\text { Hypertension } \\
\text { Diabetes mellitus } \\
\text { Digestive disease } \\
\text { Others (bronchiectasis, rheumatoid disease, gynecologic } \\
\text { diseases) }\end{array}$ & $\begin{array}{l}5(13.9) \\
2(5.6) \\
1(2.8) \\
7(19.4)\end{array}$ & $\begin{array}{l}25(36.8) \\
4(5.9) \\
2(2.9) \\
4(5.9)\end{array}$ & .04 \\
\hline $\begin{array}{l}\text { ASA physical status class } \\
\text { I } \\
\text { II }\end{array}$ & $\begin{array}{l}21(58.3) \\
15(41.7)\end{array}$ & $\begin{array}{l}43(63.2) \\
25(36.8)\end{array}$ & .67 \\
\hline $\begin{array}{l}\text { MGFA classification } \\
\text { I } \\
\text { II } \\
\text { III } \\
\text { IV }\end{array}$ & $\begin{array}{c}12(33.3) \\
11(30.6) \\
9(25) \\
4(11.1)\end{array}$ & $\begin{array}{c}31(47.1) \\
21(30.9) \\
10(14.7) \\
6(8.8)\end{array}$ & .76 \\
\hline $\begin{array}{l}\text { Pulmonary function tests } \\
\text { FVC, L } \\
\mathrm{FEV}_{1}, \mathrm{~L}\end{array}$ & $\begin{array}{l}87.1 \pm 16.3 \\
88.6 \pm 16.6\end{array}$ & $\begin{array}{l}88.6 \pm 21 \\
89.1 \pm 21\end{array}$ & $\begin{array}{l}.73 \\
.92\end{array}$ \\
\hline $\begin{array}{l}\text { Preoperative medication } \\
\text { Single agent } \\
\text { Two or more agents } \\
\text { AChR antibodies }+\end{array}$ & $\begin{array}{l}15(41.7) \\
21(58.3) \\
30(83.3)\end{array}$ & $\begin{array}{l}24(35.3) \\
44(64.7) \\
48(70.6)\end{array}$ & .49 \\
\hline $\begin{array}{l}\text { Preoperative duration of symptoms, mo } \\
\quad<12 \\
>12\end{array}$ & $\begin{array}{l}16(44.4) \\
20(55.6)\end{array}$ & $\begin{array}{l}20(29.4) \\
48(70.6)\end{array}$ & .14 \\
\hline Lesion size on CT images, $\mathrm{cm}$ & $3.4 \pm 1.4$ & $3.6 \pm 2.1$ & .60 \\
\hline $\begin{array}{l}\text { Pathologic diagnosis } \\
\text { Thymoma } \\
\text { Thymic hyperplasia } \\
\text { Normal thymus tissue }\end{array}$ & $\begin{aligned} 17 & (47.2) \\
18 & (50) \\
1 & (2.8)\end{aligned}$ & $\begin{array}{c}36(52.9) \\
28(41.2) \\
4(5.9)\end{array}$ & .59 \\
\hline $\begin{array}{l}\text { Masaoka stage } \\
\text { I } \\
\text { IIa } \\
\text { IIb } \\
\text { III }\end{array}$ & $\begin{aligned} 12 & (70.6) \\
2 & (11.8) \\
2 & (11.8) \\
1 & (5.9)\end{aligned}$ & $\begin{aligned} 18 & (50) \\
9 & (25) \\
5 & (13.9) \\
4 & (11.1)\end{aligned}$ & .53 \\
\hline $\begin{array}{l}\text { WHO classification } \\
\text { A } \\
\text { AB } \\
\text { B1 } \\
\text { B2 } \\
\text { B3 }\end{array}$ & $\begin{array}{l}1(5.9) \\
5(29.4) \\
2(11.8) \\
8(47.1) \\
1(5.9)\end{array}$ & $\begin{array}{c}4(11.1) \\
8(22.2) \\
9(25) \\
12(33.3) \\
3(8.3)\end{array}$ & .70 \\
\hline Adjuvant therapy & $5(29.4)$ & $5(13.9)$ & .31 \\
\hline
\end{tabular}

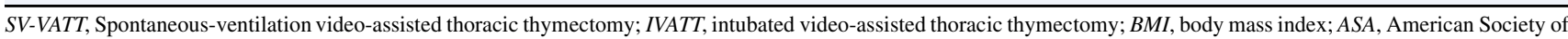
Anesthesiologists; $M G F A$, Myasthenia Gravis Foundation of America; $F V C$, forced vital capacity; $F E V_{l}$, forced expiratory volume in 1 second; $A C h R$, acetylcholine receptor; $C T$, computed tomography; WHO, World Health Organization. 
TABLE E2. Operative and anesthesia results

\begin{tabular}{|c|c|c|c|}
\hline Variable & SV-VATT & IVATT & $P$ value \\
\hline Surgical duration, min & $143.1 \pm 42.6$ & $150 \pm 58.7$ & .53 \\
\hline Lowest $\mathrm{SpO}_{2}$ during operation, $\%$ & $96.8 \pm 2.4$ & $98 \pm 2.8$ & .10 \\
\hline Peak $\mathrm{EtCO}_{2}$ during operation, $\mathrm{mm} \mathrm{Hg}$ & $41.4 \pm 3.5$ & $37 \pm 4.3$ & $<.01$ \\
\hline Conversion to tracheal intubation & $1(2.8)$ & - & - \\
\hline Intraoperative urine output, $\mathrm{mL}$ & $546.7 \pm 255$ & $477 \pm 268.9 .8$ & .21 \\
\hline
\end{tabular}

TABLE E3. Treatment outcomes

\begin{tabular}{lccc}
\hline \multicolumn{1}{c}{ Variable } & SV-VATT & IVATT & $P$ value \\
\hline Complications & $3(8.3)$ & $34(50)$ & $<.01$ \\
Sore throat & 0 & $10(14.7)$ & .01 \\
Air leak $>3 \mathrm{~d}$ & 0 & $5(7.4)$ & .16 \\
Pulmonary infection & $1(2.8)$ & $5(7.4)$ & .66 \\
Atelectasis & $1(2.8)$ & 0 & .35 \\
Myasthenic crisis & $1(2.8)$ & 0 & .02 \\
Death & 0 & $14(20.6)$ & \\
Postoperative tracheal intubation time $>1 \mathrm{~d}$ & $1(2.8)$ & $8.8 \pm 4.7$ & .02 \\
\hline Duration of postoperative hospital stay, d & $6.8 \pm 2.7$ & & \\
\hline
\end{tabular}

SV-VATT, Spontaneous-ventilation video-assisted thoracic thymectomy; IVATT, intubated video-assisted thoracic thymectomy. 